\title{
Does size matter for horny beetles? A geometric morphometric analysis of interspecific and intersexual size and shape variation in Colophon haughtoni Barnard, 1929, and C. kawaii Mizukami, 1997 (Coleoptera: Lucanidae)
}

\author{
Thea Eldred $^{1} \cdot$ Carlo Meloro $^{2} \cdot$ Clarke Scholtz $^{3} \cdot$ Declan Murphy $^{1} \cdot$ \\ Katie Fincken $^{1}$ - Matt Hayward ${ }^{4}$
}

Received: 28 December 2015 / Accepted: 17 May 2016

(C) The Author(s) 2016. This article is published with open access at Springerlink.com

\begin{abstract}
Colophon is an understudied, rare and endangered stag beetle genus with all species endemic to isolated mountain peaks in South Africa's Western Cape. Geometric morphometrics was used to analyse intersexual and interspecific variation of size and shape in the mandibles, heads, pronota and elytra of two sympatric species: Colophon haughtoni and Colophon kawaii. All measured structures showed significant sexual dimorphism, which may result from male-male competition for females. Female mandibles were too small and featureless for analysis, but male Colophon beetles possess large, ornate mandibles for fighting. Males had significantly larger heads and pronota that demonstrated shape changes which may relate to resource diversion to the mandibles and their supporting structures. Females are indistinguishable across species, but males were accurately identified using mandibles, heads and pronota. Male C. kawaii were significantly larger than $C$. haughtoni for all structures. These results support the species status of $C$. kawaii, which is currently in doubt due to its hybridisation with $C$. haughtoni. We also demonstrate the value of geometric morphometrics as a tool which may aid Colophon conservation by providing
\end{abstract}

Thea Eldred

theaeldred@gmail.com

School of Biological Sciences, Bangor University, Gwynedd, UK

2 Research Centre in Evolutionary Anthropology and Palaeoecology, School of Natural Sciences and Psychology, Liverpool John Moores University, Liverpool, UK

3 Department of Zoology and Entomology, University of Pretoria, Pretoria, South Africa

4 School of Environment, Natural Resources and Geography and School of Biological Sciences, Bangor University, Gwynedd, UK biological and phylogenetic insights and enabling species identification.

Keywords Colophon $\cdot$ Lucanidae $\cdot$ Geometric morphometrics $\cdot$ Morphology $\cdot$ Species identification · Sexual dimorphism

\section{Introduction}

Colophon Gray, 1832, is a genus of endangered montane stag beetles (subfamily Lucaninae Latreille, 1804 (Kim and Farrell 2015)) endemic to the Western Cape Province of South Africa (Fig. 1) (Geertsema and Owen 2007; Switala et al. 2015). The first species was described by Gray (1832) in 1832, but over 180 years later, we still know very little about these understudied beetles.

\section{Colophon biology}

The genus Colophon comprises 17 known species, each endemic to a particular mountain peak or range. All species are slow-moving and flightless, with adult activity spanning October to March (Barnard 1929; Endrödy-Younga 1986; Geertsema and Owen 2007). They inhabit montane fynbos habitats and are closely associated with Restionaceae bushes (Barnard 1929; Brinck 1956). Little else is known about the ecology, demography, physiology or behaviour of the genus (Geertsema and Owen 2007; Roets et al. 2013).

\section{Colophon conservation}

Colophon beetles are a research and conservation priority. Locally endemic species are especially vulnerable to 
extinction (Van Dyke 2008; Pizzo et al. 2011), and the restriction of Colophon species to the Western Cape mountain peaks makes them particularly vulnerable to global warming (Parmesan et al. 1999; Switala et al. 2015). Construction projects are damaging and reducing the already limited habitats of some populations (Geertsema and Owen 2007), and all Colophon species are threatened by illegal collection, with single specimens being sold for up to US $\$ 15,000$ on the black market (Beeton 1997; Melisch and Schütz 2000). Colophon is an important flagship taxon for campaigns against illegal insect trade (New 2009), and all species are listed on CITES Appendix III (CITES 2015). The genus was added to the South African ToPS list in 2007 and species are also categorised from vulnerable to critically endangered on the IUCN Red List (IUCN 2015). However, these assessments need updating (IUCN 2015) and the effective management and conservation of Colophon is impaired by the paucity of knowledge on their natural history (New 2009; Roets et al. 2013).

\section{Morphology}

This study is the first attempt to statistically examine morphological variation in Colophon stag beetles. As morphology is determined by both genotype and phenotype, it can provide insights into the phylogeny and ecology of Colophon beetles and the selective pressures driving their evolution (Losos and Miles 1994). A morphological study can also aid the development of a reliable and accurate identification method for this genus, which is fundamental to studying Colophon biology and ultimately to conserving the genus.

Traditionally, shape analysis relied on qualitative descriptions and linear measurements. These were often inadequate for describing the complexity of many organisms and the slight (but significant) variations between them. Modern geometric morphometrics provide a fast, cheap and accurate method for the detection, quantification and visualisation of subtle shape changes between organisms even at the intraspecific level (Bookstein 1997; Alibert et al. 2001; Adams et al. 2004, 2013).

\section{Colophon morpho-taxonomy}

Colophon morphology was first investigated by EndrödyYounga (1986), who used morphological characters to create a dichotomous key for the genus and hypothesise phylogenetic relationships between species. Switala et al. (2014) have recently confirmed these predictions using molecular techniques highlighting the value of morphology as a reliable and powerful taxonomic tool. The phylogenetic placement of one species, Colophon kawaii, remains unsolved (Switala et al. 2014). This species was undiscovered during Endrödy-Younga's study and is consequently not included in the identification key for the genus. Furthermore, Switala et al. analysed only two kawaii specimens, which either grouped as sister to Colophon cameroni Barnard 1929, or nested within Colophon haughtoni. The species status of kawaii is further confounded by molecular evidence for its hybridisation with haughtoni, with which it occurs sympatrically in the Hex River Mountains (Switala 2013; Switala et al. 2014). Geometric morphometrics have been successfully used to distinguish honeybee subspecies (Apis mellifera Linnaeus, 1761; Hymenoptera: Apidae) (Tofilski 2008) and to identify cryptic Nebriola ground beetle species (Coleoptera: Carabidae) (Roggero et al. 2013), and similar methods could shed light on Colophon systematics.

\section{Sexual dimorphism in Colophon}

Male Colophon possesses large mandibles which are highly diverse and species-specific in shape. By contrast, female mandibles are small, non-diagnostic structures (EndrödyYounga 1986). Such sexual dimorphism may result from male-male competition for females; sex ratios in this genus appear to be male-biased for all species and male Colophon have been observed to attack each other using their mandibles (Geertsema and Owen 2007; T.E., personal observation). Male beetle weaponry is often positively allometric with body size (Petrie 1988; Kawano 1997; Kodric-Brown et al. 2006) and larger weapons and/ or body sizes improve a males fighting success (Moczek and Emlen 2000; Moczek 2006). This favours sexual selection for increasingly large, weaponised males and is a likely driver of sexual dimorphism in many Coleopteran species including Colophon (Bonduriansky 2007; Painting and Holwell 2013). Identifying and quantifying sexual dimorphism in Colophon is the first step towards a full understanding of the selective pressures driving their evolution (Emlen 1997; Moczek 2006).

\section{Aims and hypotheses}

This study will focus on two sympatric species: C. haughtoni and C. kawaii. The research need for these species is highlighted by the IUCN Red List (IUCN 2015); the conservation status of $C$. haughtoni is endangered but requires updating, whilst C. kawaii is not even listed. Switala (2013) suggests that the latter species is critically endangered. Geometric morphometrics will be employed to quantify, visualise and test the statistical significance of interspecific and intraspecific size and shape variation in Colophon using four structures: the mandible, head, pronotum and elytron. Two hypotheses will be tested: (1) all of the above structures demonstrate sexual dimorphism in the species $C$. haughtoni and C. kawaii, and (2) all listed structures differ significantly in size and shape between male $C$. haughtoni and male $C$. kawaii beetles. Two additional aims of this study are (i) to provide support for the hypothesis that $C$. kawaii is a distinct species by testing the degree of morphological separation between male C. haughtoni and C. kawaii and (ii) evaluate the 
accuracy and value of geometric morphometrics as a tool for identifying Colophon species.

\section{Methods}

\section{Data collection}

Data were collected near the peak of Matroosberg Mountain by searching under shrubs for dead beetle fragments (4 November 2014-10 January 2015; location $33^{\circ} 23^{\prime} \mathrm{S}, 19^{\circ} 40^{\prime} \mathrm{E}, 2231 \mathrm{~m}$; CapeNature Permit 0056-AAA007-00129). Sexes were distinguished using the mandibles, but females could not be identified to species level due to their extreme similarity and the consequent lack of any taxonomic key. Male Colophon beetles were identified using traditional qualitative characters based on Endrödy-Younga's (1986) dichotomous key. As previously mentioned, this key does not include $C$. kawaii. However, Endrödy-Younga describes how C. haughtoni can be distinguished from other Colophon species by the presence of "a flattened shiny surface" which connects the apex of the mandible and the dorsal process (see Fig. 1 for anatomical characters). This structure was found to be absent in C. kawaii (Figs. 1 and 2), and so can be used as a basic, qualitative character to differentiate between these two species.

Fragmentary specimens were organised into the following groups: male haughtoni, male kawaii, females and "unidentified" Colophon individuals whose species and sex could not be determined. Complete specimens were dissected into the head, prothorax and abdomen. Pronota were separated from the prosterna and associated legs, and the elytra were separated from the abdomens and legs. This flattened out the pronota and elytra and avoided errors associated with placing 2D landmarks on a 3D object (Cardini 2014). Segments were photographed by placing them on a stage with graph paper underneath. All segments were photographed dorsally, and heads were also photographed ventrally to view the mandibles. A camera (Panasonic Lumix DMC-FT2 with a $28 \mathrm{~mm}$ lens) was mounted above with the lens at a distance of $350 \mathrm{~mm}$ from the stage. The camera was set at an angle parallel to the stage using a spirit level. Fragments were placed in the centre of the image, which preliminary tests showed was free from distortion. Four datasets were created: mandible $(n C$. haughtoni $=39 ;$, $C$. kawaii $=12$ ); head ( $n$ C. haughtoni $=57$; $n$ C. kawaii $=13 ; n$ female $=19)$; pronotum ( $n C$. haughtoni $=32 ; n$ C. kawaii $=11 ; n$ female $=26$; $n$ unidentified $=104)$ and elytron $(n C$. haughtoni $=20 ; n C$. kawaii $=33$; $n$ female $=10 ; n$ unidentified $=113$ ).

\section{Geometric morphometrics}

Geometric morphometrics is the analysis of shape using geometric Cartesian coordinates instead of traditional qualitative

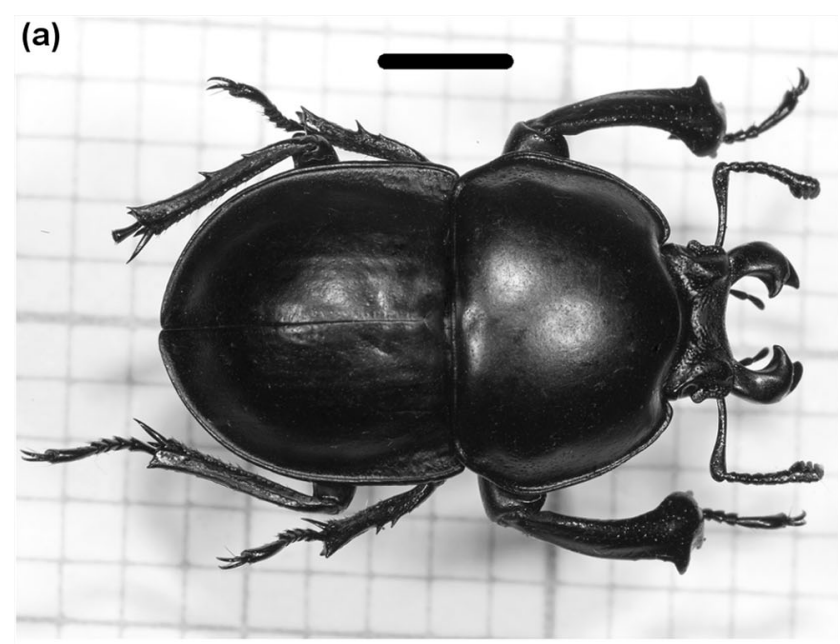

(b)

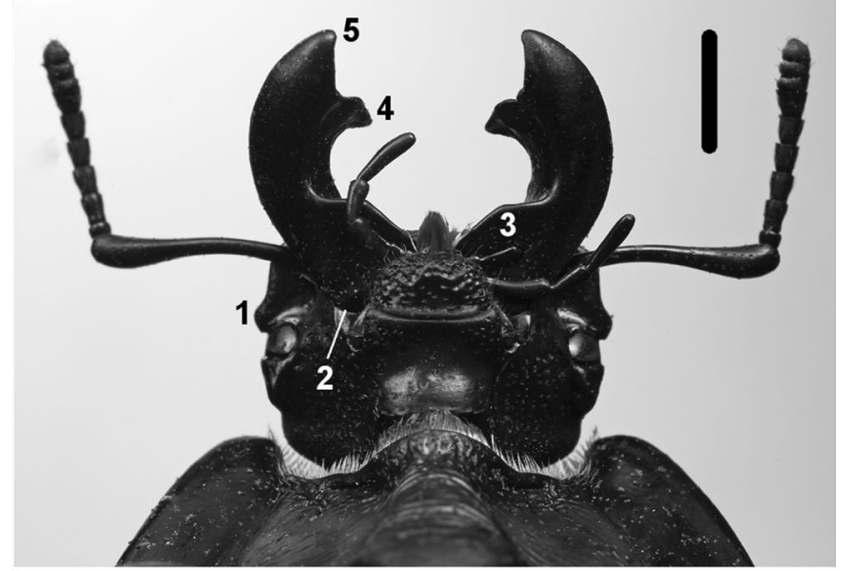

(c)

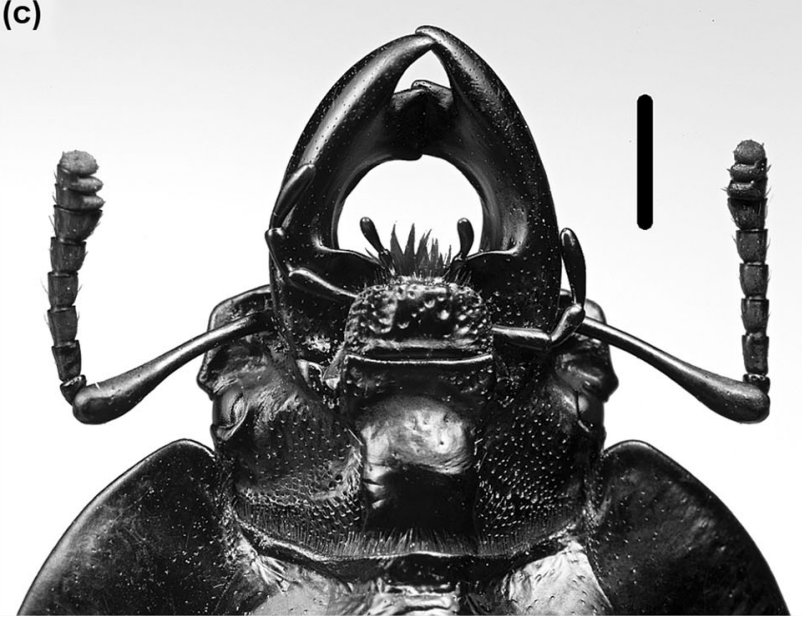

Fig. 1 Adult Colophon beetles. a Colophon haughtoni. b Ventral photograph of $C$. haughtoni head showing (1) gena, (2) mandible base, (3) ventral process, (4) dorsal process and (5) apex of the mandible. c Ventral view of C. kawaii head. Scale bars represent $4 \mathrm{~mm}$ (a) and $2 \mathrm{~mm}$ (b, c). Photographs by H.J. de Klerk

variables or linear measurements (Zelditch et al. 2004). In geometric morphometrics, the shape of organisms is described using a series of landmarks which are defined as discrete 
(a)

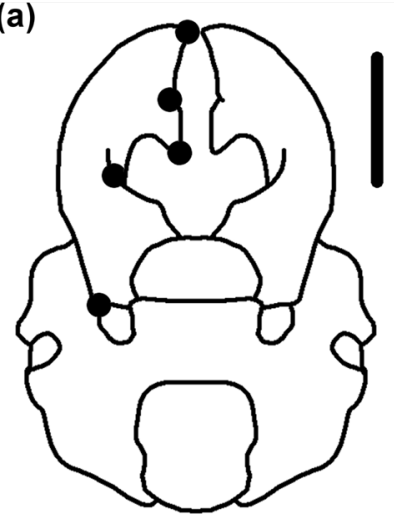

(c)

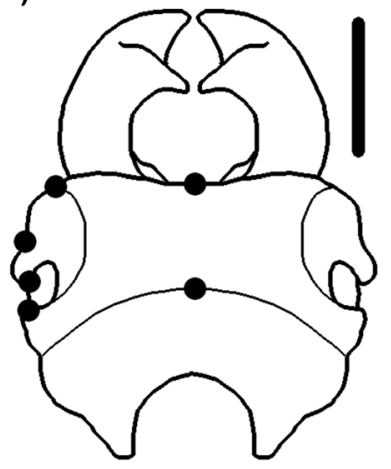

(e)

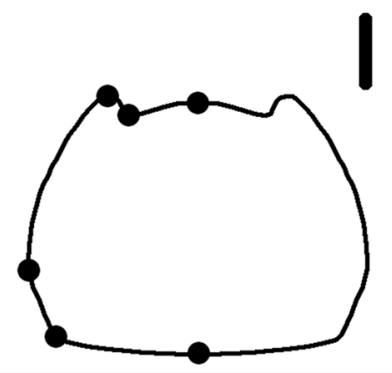

(b)

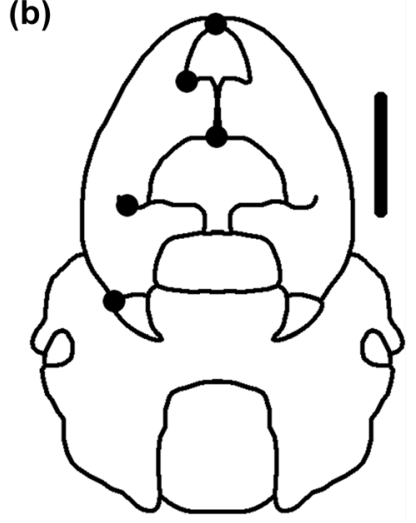

(d)

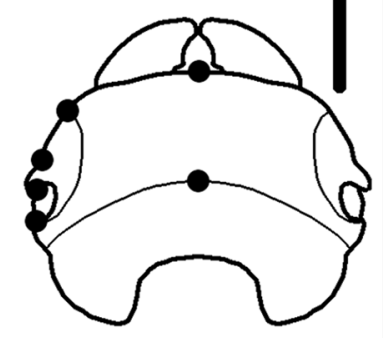

(f)

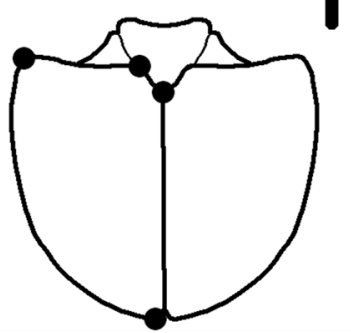

Fig. 2 Landmarks used for geometric morphometric analysis of Colophon specimens: a male C. haughtoni mandible; b male C. kawaii mandible; c male $C$. haughtoni head; $\mathbf{d}$ female head; e pronotum; $\mathbf{f}$ elytron. Scale bars represent $2 \mathrm{~mm}$

anatomical loci that are homologous across all specimens in the study (Zelditch et al. 2004). Shape information can be extracted from landmark coordinates and subjected to multivariate statistical analysis in order to answer a wide range of biological questions (Adams et al. 2004, 2013).

For each dataset, in this study, landmarks were digitised on photographs using tpsDig2 ver. 2.17 (Rohlf 2013; 2015; Fig. 2). Only the left side of structures were digitised to avoid bias caused by bilateral asymmetry (Marrone et al. 2014). Mandibles were analysed for males only as female mandibles were too small to reliably identify homologous landmarks. Procrustes superimposition was performed in MorphoJ ver.

$1.06 \mathrm{~b}$ (Klingenberg 2011) to scale, translate and rotate the landmark coordinates and produce Procrustes coordinates which contain information on shape only.

\section{Shape variation and visualisation}

A covariance matrix of the shape coordinates was generated in MorphoJ, and a principal component analysis (PCA) was performed on the matrix (preliminarily excluding unidentified beetles). Shape variation was visualised along each PC axis using thin-plate spline deformation grids produced in tpsRelw ver. 1.53 (Rohlf 2013, 2015).

\section{Size and allometry}

The size differences between groups (female, C. haughtoni, C. kawaii) were tested for statistical significance using IBM SPSS Statistics 22. Each dataset was analysed separately. The natural $\log$ transformed centroid size (LnCS) was used as a measure of size for each individual. Centroid size is the square root of the summed squared distances between all landmarks and their centre of gravity or centroid (Bookstein 1997). A Shapiro-Wilk test showed that all LnCS distributions were normal $(p>0.05)$. Levene's test assessed the datasets for homogeneity of variances. The mandible and elytron datasets were then tested for differences between species and sexes using a one-way ANOVA followed by Tukey post hoc tests to determine which groups differed significantly in LnCS. The head and pronotum datasets showed significant heterogeneity of variances $(p<0.05)$, so Welch's ANOVAs and GamesHowell post hoc tests were applied instead.

A multivariate regression in tpsRegr ver. 1.41 (Rohlf 2013, 2015) tested for allometric effects by regressing partial warps (dependent variable) on LnCS (independent variable). Partial warps are shape variables calculated in tpsRegr from the raw landmark data. "Unidentified" beetles were again preliminarily excluded and each dataset was analysed separately. Deformation grids for the smallest, middle sized and largest individuals were constructed in tpsRegr to visualise the shape deformations associated with size changes.

\section{Group classification and differentiation}

The software PAST (Hammer et al. 2001) was used to test the significance of shape differences between male C. haughtoni, male $C$. kawaii and females (unidentified beetles were excluded). One-way non-parametric MANOVAs based on the Euclidean distance measure were performed on the PC scores for the mandible, head, pronotum and elytron datasets. Significance levels were calculated by permutation of beetle group membership with 9999 permutations. Pairwise nonparametric MANOVAs between all pairs of groups were implemented as post hoc tests. 
Discriminant function analyses (DFA) using crossvalidation methods were performed in IBM SPSS Statistics 22 to statistically test the ability of size and shape variables to predict which beetle group a specimen belonged to. Beetle category (male C. haughtoni, male C. kawaii and female) was used as the factor and LnCS and principal component (PC) scores were used as independent variables. Unidentified individuals were included and categorised as unknown. Procrustes coordinates and LnCS were also used as independent variables but were less accurate and so were discarded (see also Meloro 2011 and Meloro et al. 2015). Stepwise methods were employed, and a variable was entered into the model if the probability of its $F$ value was greater than 0.05 and removed if the probability value was lower than 0.10 .

\section{Results}

\section{Shape variation and visualisation}

The mandible PCA shows two distinct clusters for C. haughtoni and C. kawaii when PC1 is plotted against PC2 (Fig. 3a). Together, PC1 and PC2 explain $83.63 \%$ of total variance in the sample. C. haughtoni specimens are grouped at the extreme right of $\mathrm{PC} 1$ and are shown in the thin-plate spline to be more elongated with a longer ventral process (see Fig. 1 for anatomical traits). C. kawaii mandibles group at the extreme negative of $\mathrm{PC} 1$, being characterised by a squatter overall shape with a relatively short ventral process and a pronounced indent between the apex and dorsal process of the mandible.

PC1 and PC2 explain $77.89 \%$ of variance in the head PCA (Fig. 3b). This plot produces a total separation between male and female beetles along PC1, which mainly describes the relative length of the head. The thin-plate splines show females to have a protruding "forehead" or frons whilst males have a larger pre-orbital area at the front corner of the head (represented by the top left landmark in Fig. 3b). Although heterospecific males show substantial overlap in shape space, kawaii specimens are positioned more towards the positive end of the PC2 axis which describes a shorter, broader head shape than for haughtoni males.

Pronotum shape also produces a good separation of sexes (Fig. 3c). PC1 and PC2 explain $80.77 \%$ of the total variance in this structure and display differences between sexes and heterospecific males, respectively. Females are distributed at the positive end of $\mathrm{PC} 1$ and their pronota are slightly squatter and have shorter, narrower anterior regions compared to males. C. kawaii males have more protrusive shoulders than females and haughtoni males.

$\mathrm{PC} 1$ and $\mathrm{PC} 2$ explain $86.56 \%$ of variation in the elytra (Fig. 3d). This plot does not show any separation between groups but males generally have lower PC1 scores than females. Thin-plate splines show that PC1 describes the relative elytron length and that male beetles have relatively shorter elytra compared to females. Changes on PC2 relates to a relative enlargement (negative scores) or shortening (positive scores) of the anterior edge of the elytra (Fig. 3d).

\section{Size and allometry}

Females consistently have the smallest LnCS for each body structure followed by male $C$. haughtoni, followed by male C. kawaii (Fig. 4a-d). ANOVAs and post hoc tests showed highly significant differences between all groups for the LnCS of every body structure (Table 1 ; all post hoc tests: $p \leq 0.001$ ). Regression analyses showed a significant correlation between size and shape for all body structures indicating strong allometry in all structures (Table 1). Allometry was visualised using deformation grids which depicted the shapes of the smallest and largest individuals and their deformation from the mean shape (Fig. 4a-d).

Allometry explains $15.8 \%$ of variation observed in the mandible dataset (Table 1) and deformation grids indicate a strong shape deformation from small to large mandible sizes (Fig. 4a). The smallest individual, represented by a C. haughtoni specimen, shows a contraction of the dorsal process compared to the mean shape for the sample. The largest specimen, a C. kawaii, shows an expansion of this region compared to the mean and a more pronounced indent between the dorsal process and the mandibular apex. The ventral process and apex are relatively shorter in the largest beetle.

Allometry accounts for $41.96 \%$ of the total shape variation in Colophon heads (Table 1). Smaller individuals are characterised by more elongated, convex heads, as represented by the two landmarks on the right side of the deformation grids in Fig. 4b. Larger specimens have comparatively shorter heads, smaller eyes and larger genal and pre-orbital regions.

Allometry explains $42.68 \%$ of pronotal shape variation (Table 1). Deformation grids demonstrate that the smallest pronota are wide at the base but become increasingly narrower and shorter towards anterior portions (Fig. 4c). Larger pronota show the opposite trend of having enlarged anterior regions and contracted posterior regions.

Allometry explains $20.2 \%$ of variation observed in the elytron dataset. The smallest elytron has a smaller and more posteriorly placed scutellum compared to the mean, whilst the largest elytron depicts a larger, longer scutellum which extends further anteriorly compared to the mean (represented by the bottom right landmarks in Fig. 4d).

\section{Group differentiation and classification}

Non-parametric MANOVAs showed that morphometric differences between male $C$. haughtoni, male $C$. kawaii and female Colophon were significant for all measured structures 
Fig. 3 Plots of the first two principal component (PC) scores obtained from principal component analyses on the shapes of four structures in Colophon beetles: a mandible, $\mathbf{b}$ head, $\mathbf{c}$ pronotum and $\mathbf{d}$ elytron. The analysis was carried out on male C. haughtoni, male C. kawaii and female Colophon of unknown species. The values in brackets for each axis represent the percentage of shape variance explained by each PC. Deformation grids show the shape change from the consensus to the extreme positive and negative of each PC axis

$(p \leq 0.02$; Table 2). DFAs indicated that size and shape data from the mandibles, heads and pronota could be used to accurately predict the sex and species status of $C$. haughtoni and C. kawaii (Table 3). Data from the elytra could be used to accurately classify male $C$. kawaii and females, but not male C. haughtoni (Table 3).

The DFA for the mandible dataset selected LnCS, PC1, PC2, PC3, and PC4 (in order of decreasing loading-see Table 3 (A)) to discriminate beetle groups. One significant discriminant function (DF) was extracted to distinguish between groups (Wilks $\lambda=0.091, \chi^{2}(5)=111.62, p<0.0001$ ). Following cross-validation, the percentage of correct classifications was $100 \%$ for both C. haughtoni and C. kawaii.

Two significant functions were derived for the head DFA (DF1 93.6 \% variance, Wilks $\lambda=0.041, \chi^{2}(10)=267.951$, $p<0.0001$; DF2 $6.4 \%$ variance, Wilks $\lambda=0.544$, $\left.\chi^{2}(4)=51.196, p<0.0001\right)$. PCs $1,2,4,5$ and LnCS maximally differentiated between groups (Table 3 (B)). All females, $82.5 \%$ of C. haughtoni and $84.6 \%$ of $C$. kawaii specimens, were correctly classified following cross-validation.

The pronotum DFA produced two significant DFs (DF1 $91.9 \%$ variance, Wilks $\lambda=0.108, \chi^{2}(8)=143.711$, $p<0.0001$; DF2 $8.1 \%$ variance, Wilks $\lambda=0.682$, $\left.\chi^{2}(3)=24.733, p<0.0001\right)$ loaded on LnCS, PC1, PC2 and PC8 (Table $3(\mathrm{C})$ ). The percentage of correct classifications were high for all cross-validated groups (females $96.2 \%$; C. haughtoni $90.6 \%$; C. kawaii $72.7 \%$ ).

Although beetle groups could not be separated by plotting elytron PC1 values against PC2 values, two significant discriminant functions were selected for in the DFA (DF1 95.4\% variance, Wilks $\lambda=0.264, \chi^{2}(6)=78.683, p<0.0001$; DF2 $4.6 \%$ variance, Wilks $\left.\lambda=0.896, \chi^{2}(2)=6.458, p<0.0001\right)$. LnCS, PC1 and PC2 were the variables which most separated the groups (Table 3 (D)). Females (85\%) and C. kawaii $(80 \%)$ showed high percentages of correct classifications, whilst $C$. haughtoni was correctly classified only $66.7 \%$ of the time after cross-validation.

\section{Discussion}

This study has made the first exploration of Colophon morphology using geometric morphometrics. C. kawaii is found at only one location where it occurs sympatrically with C. haughtoni (Switala 2013), but there is currently no standard
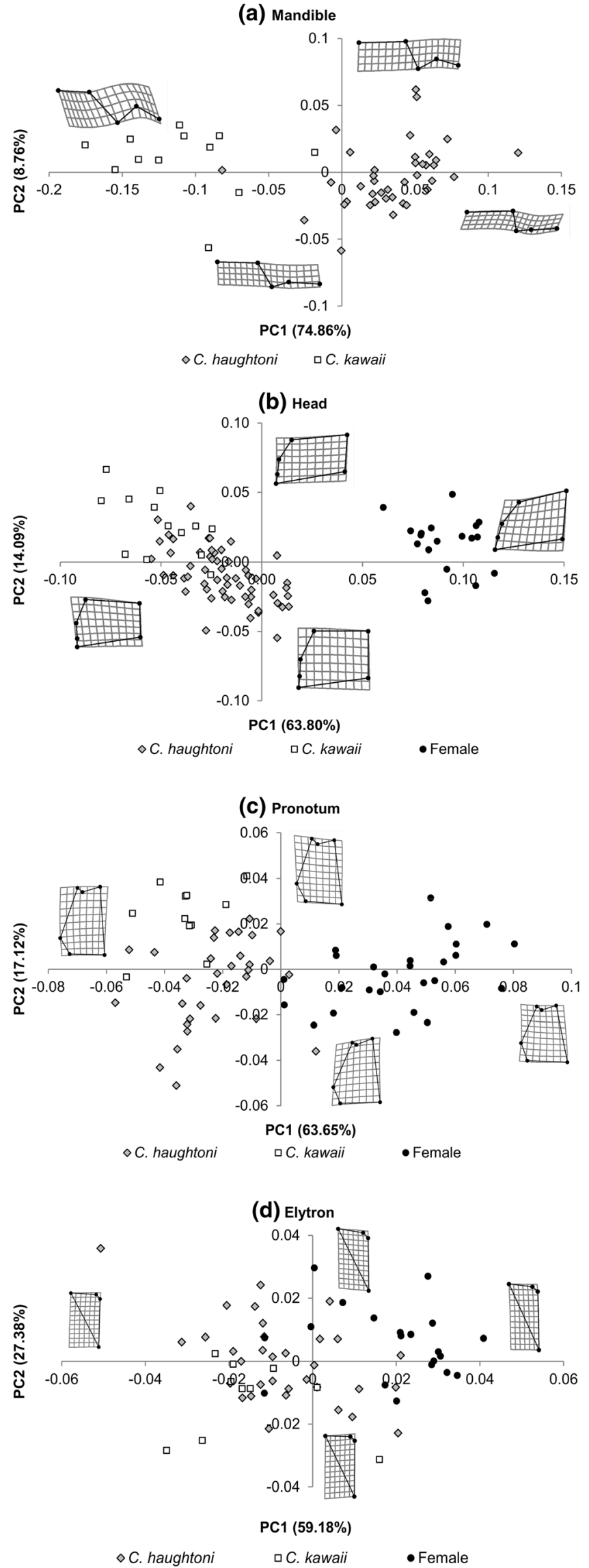
Fig. 4 Box plots and deformation grids showing size variations and shape deformations in Colophon beetles: female Colophon, male C. haughtoni and male C. kawaii. Size was measured as natural log transformed centroid size (LnCS). Deformation grids show the shape changes related to size from the smallest to the largest individuals. Values in parentheses are the magnification applied to improve visualisation of shape deformations (a) Mandible
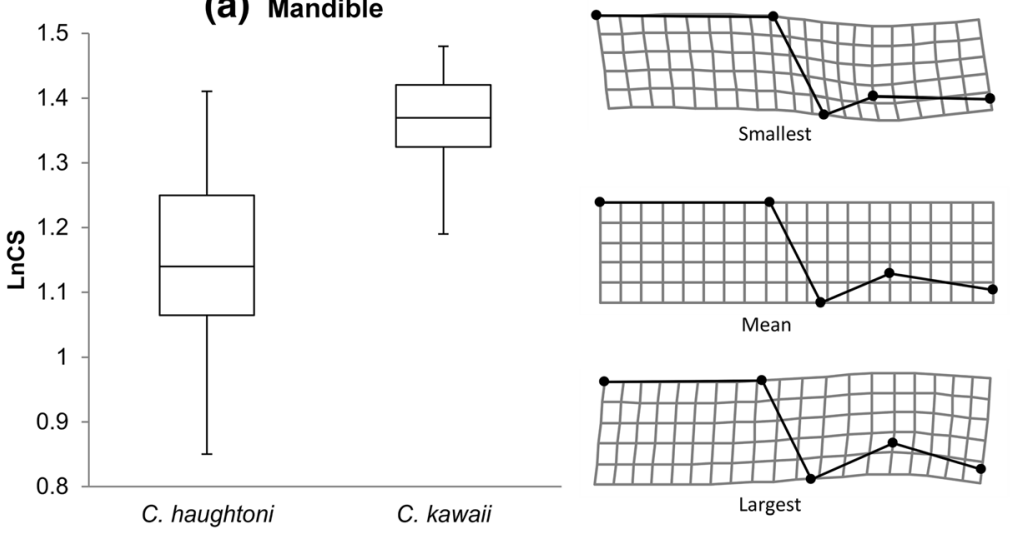

Largest
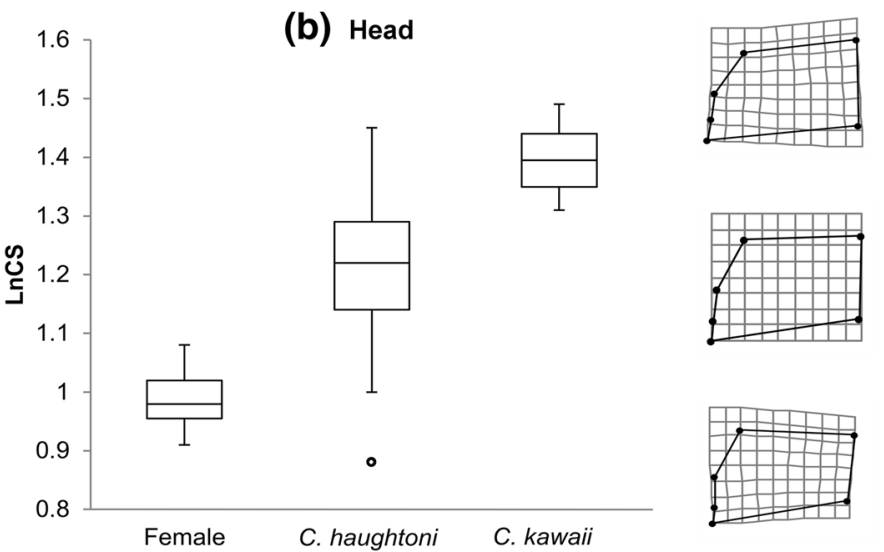

Smallest

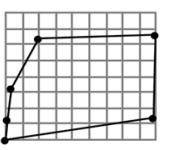

Mean

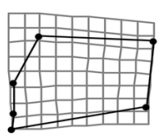

Largest
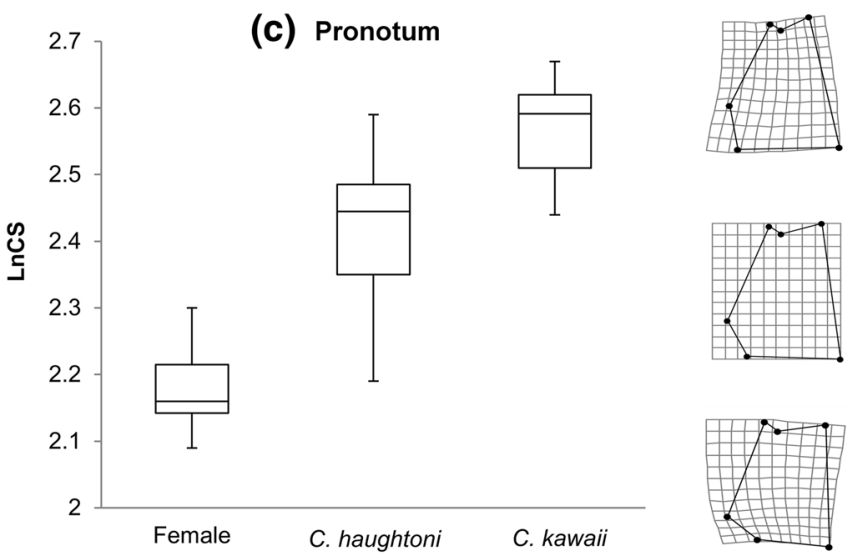

Smallest (x3)

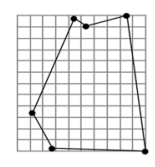

Mean

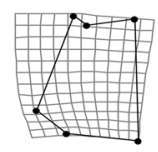

Largest (x3)

(d) Elytron

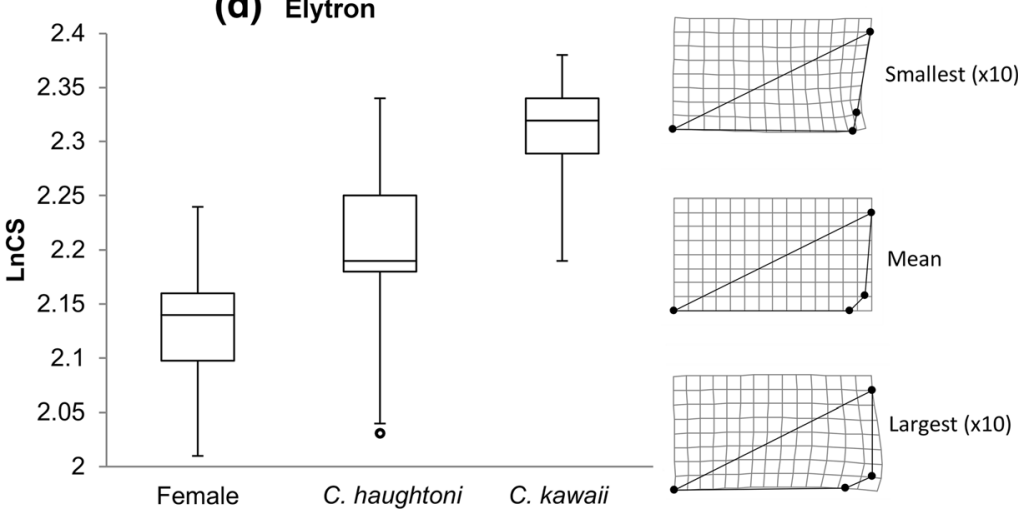


Table 1 Size variation and allometry in male C. haughtoni, male C. kawaii and female Colophon (species unknown)

\begin{tabular}{|c|c|c|c|c|c|c|c|}
\hline & \multicolumn{3}{|c|}{ ANOVA } & \multirow[t]{2}{*}{$\%$ expl. var. } & \multicolumn{3}{|c|}{ Goodall's $F$ test } \\
\hline & $F$ ratio & $d f$ & $p$ value & & $F$ ratio & $d f$ & $p$ value \\
\hline Mandible & 30.92 & 1,49 & $<0.0001$ & $15.80 \%$ & 9.25 & 6,294 & $<0.0001$ \\
\hline Head & 241.9 & $2,36.64$ & $<0.0001$ & $41.96 \%$ & 63.07 & 8,696 & $<0.0001$ \\
\hline Pronotum & 145.28 & $2,27.14$ & $<0.0001$ & $42.68 \%$ & 49.94 & 8,536 & $<0.0001$ \\
\hline Elytron & 31.42 & 2,60 & $<0.0001$ & $20.21 \%$ & 15.45 & 4,244 & $<0.0001$ \\
\hline
\end{tabular}

ANOVAs tested for significant differences in the natural logarithm of centroid size ( $\mathrm{LnCS}$ ) between beetle groups. Shape variables were regressed on LnCS to test for allometry in each structure. \% expl. var. is the variation in each dataset explained by size. Goodall's $F$ test analyses the significance of the regression method for discriminating between these species. We identified a structure (a flattened shiny surface connecting the mandible apex with the dorsal process (Fig. 1)) which is present in C. haughtoni but absent in C. kawaii and so can be used as a basic qualitative character for distinguishing these species. However, traditional qualitative morphometric characters cannot be subjected to statistical analysis or demonstrate the significance of morphological variations in the genus (Bookstein 1997; Alibert et al. 2001; Adams et al. 2004, 2013). Modern geometric morphometric methods provide a new, analytical perspective which advance the taxonomy of this genus, enable the visualisation of previously undetected shape changes and allow us to answer a range of biological questions regarding C. haughtoni and C. kawaii.

We found that sexual dimorphism is significant in the heads, pronota and elytra of these species (hypothesis 1). The morphology of the mandibles, heads, pronota and elytra also differs significantly between male $C$. haughtoni and male C. kawaii (hypothesis 2). This result fulfils our first aim by giving support to the hypothesis that $C$. kawaii is a distinct species. We were able to accurately distinguish sexes and

Table 2 Results of non-parametric MANOVAs (9999 permutations) and pairwise comparisons performed on principal component scores from the mandibles, heads, pronota and elytra of male Colophon haughtoni, male C. kawaii and female Colophon (species unknown)

\begin{tabular}{|c|c|c|c|c|c|}
\hline & \multicolumn{2}{|c|}{ MANOVA } & \multicolumn{3}{|c|}{ Pairwise comparisons } \\
\hline & $F$ & $p$ & Groups & $F$ & $p$ \\
\hline Mandible & 65.17 & 0.001 & $h a u \times k a w$ & 65.17 & 0.001 \\
\hline \multirow[t]{3}{*}{ Head } & \multirow[t]{3}{*}{70.09} & \multirow[t]{3}{*}{0.0001} & $h a u \times k a w$ & 16.32 & 0.0001 \\
\hline & & & $h a u \times$ fem & 110.3 & 0.0001 \\
\hline & & & $k a w \times f e m$ & 93.45 & 0.0001 \\
\hline \multirow[t]{3}{*}{ Pronotum } & \multirow[t]{3}{*}{38.33} & \multirow[t]{3}{*}{0.0001} & $h a u \times k a w$ & 9.392 & 0.0001 \\
\hline & & & $h a u \times$ fem & 53.83 & 0.0001 \\
\hline & & & $k a w \times$ fem & 42.76 & 0.0001 \\
\hline \multirow[t]{3}{*}{ Elytron } & \multirow[t]{3}{*}{14.38} & \multirow[t]{3}{*}{0.0001} & $h a u \times k a w$ & 3.629 & 0.02 \\
\hline & & & $h a u \times$ fem & 19.22 & 0.0001 \\
\hline & & & $k a w \times$ fem & 21.35 & 0.0001 \\
\hline
\end{tabular}

males of different species, suggesting geometric morphometrics are a powerful tool for the classification of C. haughtoni and C. kawaii (aim (ii)).

Table 3 Canonical discriminant coefficients and loadings for the discriminant function analyses applied to body structures of Colophon beetles

\begin{tabular}{|c|c|c|c|}
\hline \multicolumn{2}{|c|}{ Standardised coefficient } & \multicolumn{2}{|l|}{ Loading } \\
\hline Function 1 & Function 2 & Function 1 & Function 2 \\
\hline
\end{tabular}

(A) Mandible ${ }^{\mathrm{a}}$

$\begin{array}{lll}\text { LnCS } & -0.634 & -0.251 \\ \text { PC1 } & 1.342 & 0.545 \\ \text { PC2 } & -0.490 & -0.073 \\ \text { PC3 } & 0.603 & 0.088 \\ \text { PC4 } & -0.604 & -0.034\end{array}$

(B) Head

$\begin{array}{lllll}\text { PC1 } & 1.133 & 0.125 & 0.785 & -0.443 \\ \text { PC2 } & 0.723 & 0.775 & 0.08 & 0.732 \\ \text { PC4 } & 0.094 & 0.552 & 0.007 & 0.344 \\ \text { PC5 } & -0.307 & -0.003 & -0.021 & -0.072 \\ \text { LnCS } & -0.135 & 0.491 & -0.336 & 0.607\end{array}$

(C) Pronotum

\begin{tabular}{cllll} 
LnCS & -0.494 & 0.164 & -0.764 & 0.172 \\
PC1 & 0.739 & 0.308 & 0.777 & 0.520 \\
PC2 & 0.285 & -0.588 & 0.152 & -0.742 \\
PC8 & -0.137 & 0.586 & -0.42 & 0.642 \\
(D) Elytra & & & & \\
LnCS & 0.688 & 0.623 & 0.657 & 0.336 \\
PC1 & 0.675 & -0.814 & 0.593 & -0.788 \\
PC2 & 0.666 & 0.331 & 0.221 & 0.451 \\
\hline
\end{tabular}

The shape (principal component (PC) scores) and size (natural logarithm of centroid size (LnCS)) of body structures were used to distinguish between male C. haughtoni, male C. kawaii and female Colophon (species unknown). The standardized coefficient indicates the contribution of each size/shape variable to the discriminant function(s) derived from the analysis. Loading represents the correlation between the discriminant function(s) and an independent variable (beetle group)

${ }^{\text {a }}$ Only one discriminant function was selected for the mandible dataset 


\section{Sexual dimorphism}

Some studies suggest natural selection, such as divergence in feeding niches, leads to shape divergence between sexes (Temeles and Roberts 1993; Temeles et al. 2000). However, unambiguous examples of ecologically driven sexual dimorphism are rare and most studies suggest sexual selection is the primary cause (Shine 1989). Observations of sexual dimorphism in this study will therefore only be discussed in relation to sexual selection.

Sexual dimorphism is evident in the mandibles of Colophon but geometric morphometrics also revealed significant size and shape differences in the head, pronotum and elytron that were not previously apparent (Table 2). Deformation grids allowed the visualisation of subtle shape changes which may have important biological functions. Regression showed that shape variation due to allometry was significant for all structures (Table 1) and females had consistently smaller LnCS values than males (Fig. 4a-d). This may be due to sexual selection for increased overall size in males, which is associated with positive allometric mandible growth and increases their success in male-male competition (Petrie 1988; Kawano 1997; Kodric-Brown et al. 2006).

\section{Head}

Female heads were significantly smaller than in males but were relatively longer with larger eye diameters and a more protrusive frons. Males had a more concave frons, a larger preorbital area and larger genae (Fig. 3a). Sexual dimorphism in Colophon heads may be related to mandibular form and function. Goyens et al. (2014) found that longer mandibles and stronger bite forces in male Cyclommatus metallifer stag beetles (Boisduval, 1835; Coleoptera: Lucanidae) are compensated for by longer input levers and larger closer muscles. These structures in turn require larger heads with broader anterior portions compared to females. A similar mechanism could explain the large size and pre-orbital region of male Colophon heads.

Male Colophon also had smaller eye diameters and wider genae than females (Fig. 3a). Okada and Miyatake (2009) observed similar trends in large-mandibled Gnatocerus cornutus Fabricius, 1798, beetles (Coleoptera: Tenebrionidae) compared to small-mandibled males. They suggest that larger genae may develop in compensation for enlarged mandibles or may be used for display in male-male competition (Okada and Miyatake 2009). Emlen (2001) demonstrated that excessive horn growth in Onthophagus Latreille, 1802, dung beetles can divert resources from nearby structures such as eyes and antennae and a similar trade-off could underlie the relatively smaller eyes of male Colophon beetles compared to females.
Male-male competition in Colophon beetles may produce sexual selection for increasing mandible size and power in males leading to corresponding sexual dimorphism in head morphometry.

\section{Pronotum}

Visual examination suggested pronotal morphology was homogenous across sexes but our analyses revealed otherwise. Size was a prominent distinguishing factor between the sexes and females had significantly smaller pronota than males of both species (Table 3, Fig. 4c). Hlavac (1969) and Okada and Miyatake (2009) suggest that larger prothoraces in male beetles may contain a greater muscle mass and energy store and so may evolve to compensate for their large mandibles and the forces produced during combat (Tomkins et al. 2005). This may also explain the expansion of male Colophon pronota towards the head region, where most support is needed (Fig. 3c).

Deformation grids also revealed that female pronota are generally squatter than in males and although they are smaller anteriorly, they are wider towards the abdomen (Fig. 3c). In contrast to male beetles, females may divert their resources posteriorly to improve their reproductive success. Preziosi et al. (1996) and Adams and Funk (1997) hypothesise that larger abdomens increase the egg carrying capacity and consequently the fecundity of female insects. Fairn et al. (2007) found that the pronota of female Dineutus nigrior Roberts, 1895, beetles (Coleoptera: Gyrinidae) were shorter compared to males and suggested this was in compensation for longer elytra and increased egg storage. Very few studies have explored pronotal sexual dimorphism in beetles but the distinctive pronotal morphology of male and female Colophon suggests that this structure may be influenced by sexual selection and so may give insight into the reproductive biology of C. haughtoni and C. kawaii.

\section{Elytron}

Although elytral shape was significantly different between all beetle groups (Table 2), considerable overlap between sexes was observed in the elytron PCA plots (Fig. 3d). This suggests that sexes are morphologically more similar in their elytra compared to other structures. Size was the most discriminating factor between males and females (Table 3 (D)), and allometric effects were primarily associated with an increase in scutellum size from small females to large males. Females tended towards a relatively longer elytron than males (Fig. 3a), and as previously discussed, this may result from selection for increased egg carrying capacity (Preziosi et al. 1996; Adams and Funk 1997). This hypothesis has been used to explain relatively wider abdomens observed in female Chilean Magnificent Beetles (Ceroglossus chilensis Eschscholtz, 
1829) (Benitez et al. 2011) and the longer abdomens in female Neochlamisus bebbianae Brown, 1943, leaf beetles (Adams and Funk 1997). The observed dimorphism in Colophon may equally be caused by selection for shorter elytra in males. Kawano (1997) found that elytral size was negatively allometric to body length in Lucanid males and Okada and Miyatake (2009) observed that increased horn growth in male G. cornutus beetles was correlated with reduced elytral length. This suggests that resources are diverted anteriorly to structures more important for competition in male beetles (Okada and Miyatake 2009). Our results indicate gender-specific trends in elytral morphology but the detection and visualisation of shape changes was probably hindered by the lack of homologous landmarks on this structure. Further studies should be conducted using semi-landmark methods (Zelditch et al. 2004; Van Bocxlaer and Schultheiß 2010).

Most studies focus on sexual dimorphism in beetle weaponry and little information is available on other body structures. However, gender-specific trends in head, pronotal and elytral shape may provide additional insight into the sexual selective pressures underlying morphological diversification.

\section{Interspecific variation}

Interspecific morphological variation was not explored in female Colophon as they could not be identified to species level and it remains for genetic methods or more detailed anatomical analyses to separate females according to species. This highlights their extreme morphological homogeneity, as is typical for most Coleopteran species (Kawano 2006; Switala 2013). Male C. haughtoni and male C. kawaii demonstrated significant morphological differences in the mandibles, heads, pronota and elytra (Table 2), and these species could be accurately classified using these structures. Size (LnCS) significantly affected shape variation in all structures (Figs. 4a-d) and made a large contribution to species separation in both PCAs and DFAs (Tables 1 and 3). C. kawaii were significantly larger than $C$. haughtoni for all structures. The results of this study showed species-specific morphological variation in C. haughtoni and C. kawaii, giving support to the hypothesis that these are distinct species that are able to hybridise.

\section{Mandible}

Coleopteran weapons are impressive not only for their size but also their diversity and male Colophon are no exception to this. C. haughtoni were shown to have a longer ventral process than C. kawaii and less distinct mandibular horns due to a flattened surface connecting the mandible apex to the dorsal process (Figs. 1 and 3a). Although all male beetle weapons are used in male-male competition, it is not yet clear why these organs are so diverse, given their common function (Emlen et al. 2005). Palmer (1978), Eberhard (1981) and Siva-Jothy
(1987) suggest that the variation in Coleopteran weapon morphology mirrors species-specific differences in how they are utilised in combat; specialised knobs and spikes may provide leverage and friction specific to particular fighting tactics (Emlen et al. 2005). Male $C$. haughtoni have been observed to use their mandibles to attack an opponent's gula (throat) or leg (T.E., personal observation). However, further observations and statistical analyses for both species are necessary to confirm whether the divergent mandible morphology of C. haughtoni and C. kawaii is related to differing combat behaviour.

Head

Compared to C. haughtoni, C. kawaii heads were bigger and broader. As previously discussed, changes in mandible size, form and function are shown to produce changes in the head morphology of male and female C. metallifer stag beetles (Goyens et al. 2014) and also between different ant species (Paul and Gronenberg 1999). The observed divergence in Colophon head shape may similarly result from the larger, differentially shaped mandibles of $C$. kawaii compared to C. haughtoni.

\section{Pronotum}

The larger pronotum in C. kawaii may be due to the increase in overall body size, but no explanation could be found for the more protrusive shoulders observed in this species (Fig. 3c). Some studies find that morphological variations are correlated with ecological factors (Forsythe 1991; Barton et al. 2011). For example, mandible length is correlated with prey size in tiger beetles (Coleoptera: Carabidae) (Pearson and Mury 1979; Ganeshaiah and Belavadi 1986) and many insect species show significant trends in body size with increasing altitude (Chown and Klok 2003). There is insufficient information on Colophon to make assumptions regarding the ecological drivers of their morphological diversification, but quantifying this diversity is the first step in elucidating the selective pressures underlying their speciation.

\section{Accuracy of geometric morphometrics}

This study has confirmed both the power and the shortcomings of geometric morphometrics for Colophon identification. Intraspecific variation could not be analysed in females without a priori species identification but the DFA distinguished them from males with $85-100 \%$ accuracy for all structures. Males could be identified to species level with $100 \%$ accuracy based on their mandibles but also with high percentages of accuracy (72.7-90.6 \%) using just heads and pronota. The remote distribution and elusive nature of Colophon poses a barrier to scientific research (Switala et al. 2015) and often 
only a few incomplete fragments are the only evidence to be found in the field (Endrödy-Younga 1986; T.E., personal observation). Scientists are heavily reliant on mandible morphology for species and sex identification (Switala 2013) but due to Colophon's relatively small size, the head and mandibles are often missing (T.E., personal observation). Whilst genetic methods are most popular for insect species identification (Behura 2006), the provincial laws protecting Colophon beetles (CITES 2015) also hinder the acquisition of fresh specimens for genetic analysis. In addition, species including C. haughtoni and kawaii inhabit private land and approval from landowners to remove these endangered and valuable beetles may be problematic (T.E., personal observation). To aid species identification in the field, Switala (2013) attempted to determine diagnostic larval characters for Colophon. However, as with many scarabaeoids, interspecific differences were too small for this purpose. Geometric morphometrics could provide a reliable, fast and cost-effective technique for Colophon identification which could be particularly valuable when attempting to map species distributions or locate new populations.

\section{Conclusion}

Prior to this study, interspecific and intersexual shape variations were observed but not yet quantified in Colophon mandibles and the morphological variation of the head, pronotum or elytra was not considered for the genus. Only C. haughtoni and $C$. kawaii were analysed in this study, but we showed that geometric morphometrics can be a powerful technique for exploring interspecific and intersexual variation in any Colophon species. These methods allowed the detection and statistical analysis of subtle shape variations that were previously unknown and identified body structures other than the mandibles that could be used for species and sex discrimination. Sexual dimorphism is evident in the mandibles of all Colophon species, but we also showed significant dimorphisms in the head, pronotum and elytra of $C$. haughtoni and $C$. kawaii. The morphological distinction of heterospecific male beetles gave support to the hypothesis that kawaii is a valid species.

Our results provided novel insights into the interspecific and intersexual shape diversity of $C$. haughtoni and C. kawaii and identified additional avenues for study. Further research on sexual dimorphism could give insight into the reproductive biology of the genus, which is currently unknown. Also, it is important to understand how sexual selection has shaped Colophon evolution (e.g. male weaponisation and hypertrophy) and whether interspecific differences in male beetles could reflect ecological adaptations such as altitudinal size variation. Finally, geometric morphometrics could help to elucidate Colophon phylogeny and create a taxonomic key for the entire genus.

Ultimately, geometric morphometrics could aid Colophon conservation by facilitating accurate species identification, thereby enabling taxon-specific, targeted conservation strategies. Thereafter, geometric morphometrics could give insight into the reproductive biology, ecology and distribution of this rare and endangered group of beetles.

Acknowledgments Thanks to Ron Duff and the Ski Club of South Africa for providing accommodation during field research and to Craghoppers for providing outdoor clothing essential for conducting field research on mountain terrain. We are also grateful to Hennie de Klerk for providing photographs of Colophon. This study was funded by the Coalbourn Charitable Trust and Bangor University.

Open Access This article is distributed under the terms of the Creative Commons Attribution 4.0 International License (http:// creativecommons.org/licenses/by/4.0/), which permits unrestricted use, distribution, and reproduction in any medium, provided you give appropriate credit to the original author(s) and the source, provide a link to the Creative Commons license, and indicate if changes were made.

\section{References}

Adams, D. C., \& Funk, D. J. (1997). Morphometric inferences on sibling species and sexual dimorphism in Neochlamisus bebbianae leaf beetles: multivariate applications of the thin-plate spline. Systematic Biology, 46(1), 180-194.

Adams, D. C., Rohlf, F. J., \& Slice, D. E. (2004). Geometric morphometrics: ten years of progress following the "revolution". Italian Journal of Zoology, 71(1), 5-16.

Adams, D. C., Rohlf, F. J., \& Slice, D. E. (2013). A field comes of age: geometric morphometrics in the 21st century. Hystrix, the Italian Journal of Mammalogy, 24(1), 7-14.

Alibert, P., Moureau, B., Dommergues, J., \& David, B. (2001). Differentiation at a microgeographical scale within two species of ground beetle, Carabus auronitens and C. nemoralis (Coleoptera, Carabidae): a geometrical morphometric approach. Zoologica Scripta, 30(4), 299-311.

Barnard, K. (1929). A study of the genus Colophon Gray (Coleoptera, Lucanidae). Transactions of the Royal Society of South Africa, 18(3), 163-182.

Barton, P. S., Gibb, H., Manning, A. D., Lindenmayer, D. B., \& Cunningham, S. A. (2011). Morphological traits as predictors of diet and microhabitat use in a diverse beetle assemblage. Biological Journal of the Linnean Society, 102(2), 301-310.

Beeton, B. (1997). Editorial Comments. TUGboat, 18(1), 5-6.

Behura, S. K. (2006). Molecular marker systems in insects: current trends and future avenues. Molecular Ecology, 15(11), 3087-3113.

Benitez, H. A., Briones, R., \& Jerez, V. (2011). Intra and inter-population morphological variation of shape and size of the Chilean magnificent beetle, Ceroglossus chilensis in the Baker River Basin, Chilean Patagonia. Journal of Insect Science, 11(1), 94.

Bonduriansky, R. (2007). Sexual selection and allometry: a critical reappraisal of the evidence and ideas. Evolution, 61(4), 838-849.

Bookstein, F. L. (1997). Morphometric tools for landmark data: geometry and biology. New York: Cambridge University Press.

Brinck, P. (1956). Coleoptera: Lucanidae. South African Animal Life, 3, 304-335.

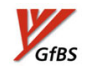


Cardini, A. (2014). Missing the third dimension in geometric morphometrics: how to assess if $2 \mathrm{D}$ images really are a good proxy for $3 \mathrm{D}$ structures? Hystrix, the Italian Journal of Mammalogy, 25(2), 73-81.

Chown, S. L., \& Klok, C. J. (2003). Altitudinal body size clines: latitudinal effects associated with changing seasonality. Ecography, 26(4), 445-455.

CITES. (2015). CITES Appendices I. URL: II and III. http://www.cites. org/eng/app/appendices.php. Accessed 13 June 2015.

Eberhard, W. G. (1981). The natural history of Doryphora sp. (Coleoptera, Chrysomelidae) and the function of its sternal horn. Annals of the Entomological Society of America, 74(5), 445-448.

Emlen, D. J. (1997). Diet alters male horn allometry in the beetle Onthophagus acuminatus (Coleoptera: Scarabaeidae). Proceedings of the Royal Society of London Series B: Biological Sciences, 264(1381), 567-574.

Emlen, D. J. (2001). Costs and the diversification of exaggerated animal structures. Science, 291(5508), 1534-1536.

Emlen, D. J., Marangelo, J., Ball, B., \& Cunningham, C. W. (2005). Diversity in the weapons of sexual selection: horn evolution in the beetle genus Onthophagus (Coleoptera: Scarabaeidae). Evolution, 59(5), 1060-1084.

Endrödy-Younga, S. (1986). Evidence for the low-altitude origin of the Cape mountain biome derived from the systematic revision of the genus Colophon Gray (Coleoptera, Lucanidae). Annals of the South African Museum, 96(9), 359-424.

Fairn, E. R., Alarie, Y., \& Schulte-Hostedde, A. I. (2007). Sexual size and shape dimorphism in Dineutus nigrior (Coleoptera: Gyrinidae). The Coleopterists Bulletin, 61(1), 113-120.

Forsythe, T. G. (1991). Feeding and locomotory functions in relation to body form in five species of ground beetle (Coleoptera: Carabidae). Journal of Zoology, 223(2), 233-263.

Ganeshaiah, K., \& Belavadi, V. (1986). Habitat segregation in four species of adult tiger beetles (Coleoptera: Cicindelidae). Ecological Entomology, 11(2), 147-154.

Geertsema, H., \& Owen, C. (2007). Notes on the habitat and adult behaviour of three red-listed Colophon spp. (Coleoptera: Lucanidae) of the Cape Floristic Region, South Africa. Beetle Conservation, 11(1), 43-46.

Goyens, J., Dirckx, J., Dierick, M., Van Hoorebeke, L., \& Aerts, P. (2014). Biomechanical determinants of bite force dimorphism in Cyclommatus metallifer stag beetles. The Journal of Experimental Biology, 217(7), 1065-1071.

Gray, G. (1832). New species of insects of all the orders. In E. Griffith (Ed.), The Animal Kingdom arranged in conformity with its organization by Baron Cuvier. London: Whittaker.

Hlavac, T. (1969). A review of the species of Scarites (Antilliscaris) (Coleoptera: Carabidae) with notes on their morphology and evolution. Psyche: A Journal of Entomology, 76(1), 1-17.

IUCN (2015). The IUCN Red List of Threatened Species. Version 2015.1. URL www.iucnredlist.org. Accessed 11 June 2015.

Kawano, K. (1997). Cost of evolving exaggerated mandibles in stag beetles (Coleoptera: Lucanidae). Annals of the Entomological Society of America, 90(4), 453-461.

Kawano, K. (2006). Sexual dimorphism and the making of oversized male characters in beetles (Coleoptera). Annals of the Entomological Society of America, 99(2), 327-341.

Kim, S. I., \& Farrell, B. D. (2015). Phylogeny of world stag beetles (Coleoptera: Lucanidae) reveals a Gondwanan origin of Darwin's stag beetle. Molecular Phylogenetics and Evolution, 86, 35-48.

Klingenberg, C. P. (2011). MorphoJ: an integrated software package for geometric morphometrics. Molecular Ecology Resources, 11(2), 353-357.

Kodric-Brown, A., Sibly, R. M., \& Brown, J. H. (2006). The allometry of ornaments and weapons. Proceedings of the National Academy of Sciences of the United States of America, 103(23), 8733-8738.
Losos, J. B., \& Miles, D. B. (1994). Adaptation, constraint, and the comparative method: phylogenetic issues and methods. In P. C. Wainwright \& S. M. Reilly (Eds.), Ecological Morphology: integrative organismal biology (pp. 60-98). Chigago, Illinois: University of Chicago Press.

Marrone, F., Deidun, A., Curatolo, T., Arculeo, M., \& Brutto, S. L. (2014). Species identification of the psammophilous tenebrionid beetles Phaleria acuminata Küster, 1852 and Phaleria bimaculata (Linnaeus, 1767) from central Mediterranean beaches: geometric morphometrics and molecular insights from species to population level. Zoomorphology, 133(1), 71-82.

Melisch, R., \& Schütz, P. (2000). Butterflies and beetles in Germany. Traffic Bulletin, 18(3), 79-132.

Meloro, C. (2011). Feeding habits of Plio-Pleistocene large carnivores as revealed by the mandibular geometry. Journal of Vertebrate Paleontology, 31(2), 428-446.

Meloro, C., Hudson, A., \& Rook, L. (2015). Feeding habits of extant and fossil canids as determined by their skull geometry. Journal of Zoology, 295(3), 178-188.

Moczek, A. P., \& Emlen, D. J. (2000). Male horn dimorphism in the scarab beetle, Onthophagus taurus: do alternative reproductive tactics favour alternative phenotypes? Animal Behaviour, 59(2), 459466.

Moczek, A. (2006). Integrating micro- and macroevolution of development through the study of horned beetles. Heredity, 97(3), 168-178.

New, T. R. (2009). Insect Species Conservation. Cambridge: Cambridge University Press.

Okada, K., \& Miyatake, T. (2009). Genetic correlations between weapons, body shape and fighting behaviour in the horned beetle Gnatocerus cornutus. Animal Behaviour, 77(5), 1057-1065.

Painting, C. J., \& Holwell, G. I. (2013). Exaggerated trait allometry, compensation and trade-offs in the New Zealand giraffe weevil (Lasiorhynchus barbicornis). PloS One, 8(11), 1-13.

Palmer, T. (1978). A horned beetle which fights. Nature, 274, 583-584.

Parmesan, C., Ryrholm, N., Stefanescu, C., Hill, J. K., Thomas, C. D., Descimon, H., Huntley, B., Kaila, L., Kullberg, J., \& Tammaru, T. (1999). Poleward shifts in geographical ranges of butterfly species associated with regional warming. Nature, 399(6736), 579-583.

Hammer, Ø., Harper, D. A. T., \& Ryan, P. D. (2001). PAST: Paleontological Statistics Software Package for Education and Data Analysis. Palaeontologia Electronica, 4(1). URL http:// palaeo-electronica.org/2001_1/past/issue1_01.htm. Accessed 13 December 2015.

Paul, J., \& Gronenberg, W. (1999). Optimizing force and velocity: mandible muscle fibre attachments in ants. The Journal of Experimental Biology, 202(7), 797-808.

Pearson, D. L., \& Mury, E. J. (1979). Character divergence and convergence among tiger beetles (Coleoptera: Cicindelidae). Ecology, 60(3), 557-566.

Petrie, M. (1988). Intraspecific variation in structures that display competitive ability: large animals invest relatively more. Animal Behaviour, 36(4), 1174-1179.

Pizzo, A., Mazzone, F., Rolando, A., \& Palestrini, C. (2011). Combination of geometric morphometric and genetic approaches applied to a debated taxonomical issue: the status of Onthophagus massai (Coleoptera, Scarabaeidae) as an endemic species vicarious to Onthophagus fracticornis in Sicily. Zoology, 114(4), 199-212.

Preziosi, R. F., Fairbairn, D. J., Roff, D. A., \& Brennan, J. M. (1996). Body size and fecundity in the waterstrider Aquarius remigis: a test of Darwin's fecundity advantage hypothesis. Oecologia, 108(3), 424- 431.

Roets, F., Pryke, J. S., \& McGeoch, M. A. (2013). Abiotic variables dictate the best monitoring times for the endangered Table Mountain stag beetle (Colophon westwoodi Gray 1832, Coleoptera: Lucanidae). Journal of Insect Conservation, 17(2), 279-285. 
Roggero, A., Giachino, P. M., \& Palestrini, C. (2013). A new cryptic ground beetle species from the Alps characterised via geometric morphometrics. Contributions to Zoology, 82(4), 171-183.

Rohlf, F. (2013). Tps series. State University of New York, Stony Brook. URL http://life.bio.sunysb.edu/morph/index.html. Accessed 10 March 2015

Rohlf, F. (2015). The tps series of software. Hystrix, the Italian Journal of Mammalogy, 26(1), 1-4.

Shine, R. (1989). Ecological causes for the evolution of sexual dimorphism: a review of the evidence. Quarterly Review of Biology, 64(4), 419-461.

Siva-Jothy, M. T. (1987). Mate securing tactics and the cost of fighting in the Japanese horned beetle, Allomyrina dichotoma L. (Scarabaeidae). Journal of Ethology, 5(2), 165-172.

Switala, A. K. (2013). Systematics and conservation of Colophon Gray (Coleoptera: Lucanidae). MSc dissertation, University of Pretoria.

Switala, A. K., Sole, C. L., \& Scholtz, C. H. (2014). Phylogeny, historical biogeography and divergence time estimates of the genus Colophon Gray (Coleoptera: Lucanidae). Invertebrate Systematics, 28(3), 326-336.

Switala, A. K., Sole, C. L., \& Scholtz, C. H. (2015). Colophon larvae: descriptions and phylogenetic implications. Insect Systematics \& Evolution, 46(1), 37-46.
Temeles, E. J., \& Roberts, W. M. (1993). Effect of sexual dimorphism in bill length on foraging behavior: an experimental analysis of hummingbirds. Oecologia, 94(1), 87-94.

Temeles, E. J., Pan, I. L., Brennan, J. L., \& Horwitt, J. N. (2000). Evidence for ecological causation of sexual dimorphism in a hummingbird. Science, 289(5478), 441-443.

Tofilski, A. (2008). Using geometric morphometrics and standard morphometry to discriminate three honeybee subspecies. Apidologie, 39(5), 558-563.

Tomkins, J. L., Kotiaho, J. S., \& Lebas, N. R. (2005). Phenotypic plasticity in the developmental integration of morphological trade-offs and secondary sexual trait compensation. Proceedings of the Royal Society of London Series B: Biological Sciences, 272(1562), 543-551.

Van Bocxlaer, B., \& Schultheiß, R. (2010). Comparison of morphometric techniques for shapes with few homologous landmarks based on machine-learning approaches to biological discrimination. Journal Information, 36(3), 497-515.

Van Dyke, F. (2008). Conservation biology: foundations, concepts, applications (2nd ed.). Netherlands: Springer Science \& Business Media.

Zelditch, M. L., Swiderski, D. L., Sheets, H. D., \& Fink, W. L. (2004). Geometric morphometrics for biologists: a primer. London: Elsevier Academic Press. 